\title{
Percepção dos Agentes Comunitários de Saúde sobre a Violência Doméstica contra a Mulher
}

Community Health Agents Perception about Domestic

Violence against Woman

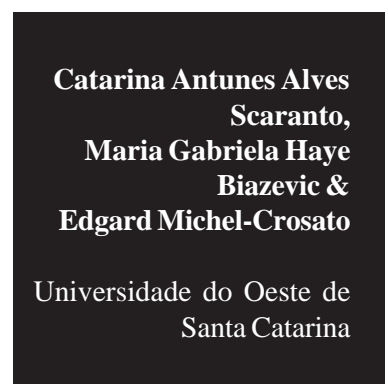

Registramos especial
agradecimento aos agentes agradecimento aos agentes comunitários de saude que
participaram do estudo e à Secretaria Municipal de Saúde do Município pela receptividade e apoio. 


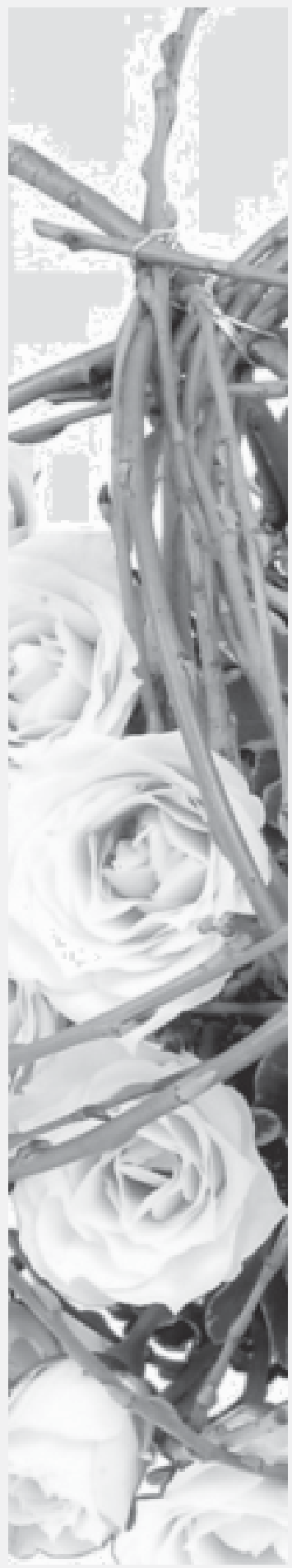

Resumo: O objetivo deste trabalho foi investigar a percepção dos agentes comunitários de saúde sobre a violência doméstica contra a mulher. Trata-se de um estudo qualitativo, descritivo e exploratório. Utilizou-se a técnica de entrevista semi-estruturada como instrumento de coleta dos dados. Foram entrevistados vinte e seis agentes comunitários de saúde, pertencentes aos vinte e cinco centros de saúde de um Município de médio porte da Região Sul do Brasil, em 2005. Para análise dos dados, empregou-se o método do discurso do sujeito coletivo. A análise dos resultados mostrou relato de violência doméstica contra a mulher pelo companheiro, seja física, sexual, psicológica ou econômica. É preciso dar subsídios teórico-práticos aos profissionais para detectar situações de violência, encontrar a forma de abordar as famílias e dar encaminhamento tanto aos casos de violência quanto de uso de álcool/drogas. A violência contra a mulher necessita ser alvo de políticas públicas consistentes e deve ser, efetivamente, considerada questão de saúde pública a partir do conceito ampliado de saúde.

Palavras-chave: violência doméstica, mulher, saúde pública, agente comunitário de saúde.

Abstract: The objective of this paper was the investigation of the community health agents perception about violence against woman. This is a qualitative study of descriptive and exploratory kind. It was developed through semi-structured interviews for the collection of data. Twenty-six community health agents who work at the 25 health centers in a medium size town in Southern Brazil were interviewed in 2005. To analyse the data it was used the collective subject speech method. The analysis of the results showed that there is domestic violence against women, either physical, sexual, psychological or economic, caused by partners. It is necessary to give theoretical and practical subsidies for the professionals to help them and to detect violence situations, find ways to get closer to the families and to deal with violence as well as with the cases of alcohol and drugs. Violence against women needs consistent public politicies, so that it can be effectively considered a question of public health from an extended concept of health.

Key words: domestic violence, woman, public health, community health agent. 
A violência contra a mulher é definida, pelas Nações Unidas, como todo ato de violência baseado no gênero que tem como resultado possível ou real um dano físico, sexual ou psicológico, incluídas as ameaças, a coerção ou a privação arbitrária da liberdade, seja na vida pública seja na vida privada (OMS/OPS, 1998).

Alves e Coura-Filho (2001, p. 244) afirmam que a violência é reconhecida pela Organização Mundial da Saúde desde 1980 “como uma questão de saúde pública, não somente do ponto de vista dos traumatismos físicos, mas também dos sérios efeitos para a saúde mental de quem a sofre”. A Organização PanAmericana de Saúde (OPAS, 1993, apud Alves e Coura-Filho, 2001) analisa que "a violência, pelo número de vítimas e a magnitude de seqüelas orgânicas e emocionais que produz, adquiriu um caráter endêmico e converteu-se em um problema de saúde pública em vários países”.

A violência doméstica possui um percurso histórico que permeia a humanidade há muitos anos, não sendo nova no contexto das sociedades. Não obstante, é recente como questão central de interesse pela comunidade e como questão de saúde pública, que pode e deve tê-la como campo de intervenções e alvo de ações específicas no âmbito das relações para seu enfrentamento.

No Brasil, desde a Constituição de 1988, garante-se o direito à proteção, à assistência da família e de todos os que a integram e também a criação, pelo Estado, de mecanismos e de formas de coibir a violência no âmbito das relações (Brasil, 1988).

Os olhares e propostas de intervenção sobre a violência começam a frutificar desde a relação entre direitos humanos e violência baseada no gênero, que vem se estabelecendo desde a década de 90, a partir de diversos documentos resultantes das Conferências Internacionais da Organização das Nações Unidas (OMS/OPS, 1998).
Um importante documento para o Brasil é a Convenção Interamericana para Prevenir, Punir e Erradicar a Violência contra a Mulher Convenção de Belém do Pará - adotada pela Assembléia Geral da Organização dos Estados Americanos, em 6 de junho de 1994, e ratificada pelo Brasil em 27 de novembro de 1995, com força de lei interna, conforme o disposto no $\S 2^{\circ}$ do artigo $5^{\circ}$ da Constituição Federal vigente (BRASIL, 1988).

Por se tratar de questão de saúde pública, e para seu enfrentamento, o Presidente do Brasil, Luís Inácio Lula da Silva, assinou, em 17 de junho de 2004, a Lei $n^{0} 10.816$, que trata a violência doméstica no Código Penal como crime, com pena de detenção de seis meses a um ano (Código Penal, 2005).

No dia 25 de novembro de 2005, data da luta para a erradicação da violência contra a mulher, o Ministério da Saúde (2005) divulgou a criação do Serviço de Notificação Compulsória da Violência contra a Mulher. A proposta era de instalação dos serviços em unidades de saúde em Municípios com capacidade de oferecêlos e que preenchessem critérios epidemiológicos estabelecidos.

Nossa sociedade está construída sob uma ordem social que permanece patriarcal. Segundo Soares (1999), os homens dominam o espaço público sem perderem a dimensão e o controle do espaço doméstico, por isso a necessidade de mudar o estado de coisas, buscando romper essa condição de as mulheres se sujeitarem a ocupar espaço bem mais limitado do que o homem. A mulher é vista como desprovida do direito de ter seus próprios sentimentos e opiniões, pois, culturalmente, o gênero hierarquiza e situa os homens acima das mulheres.

Sobre as relações entre homens e mulheres, os conceitos de sexo e gênero devem ser discutidos, já que não são sinônimos. Diferentemente do sexo, que é dado pela natureza, o gênero é uma categoria 
historicamente construída. Aprende-se a ser homem ou mulher. O gênero modela a psiquê dos seres humanos. Essa aprendizagem processa-se, segundo Saffioti (1994), não apenas com relação ao desempenho de papéis sociais mas também na formação da própria identidade dos indivíduos. Homens e mulheres são o resultado de um processo construído socialmente, em lugares, épocas e contextos diversos; são, portanto, diferentes.

Na década de 90, a violência doméstica, nas situações em que o parceiro ou ex-parceiro aparece como o agressor, passa a ser concebida de forma diferenciada, baseada nas relações de gênero e como uma questão de saúde e de direitos humanos (Schraiber et al, 2002).

O impacto social, os custos agregados de atenção à saúde, os custos à sociedade da violência contra a mulher são, portanto, enormes. Não têm sido observados estudos que tenham adotado como temática as observações feitas pelos agentes comunitários de saúde com relação à violência doméstica, muito menos na Região Sul do Brasil.

Considerando esse contexto, o objetivo do presente estudo foi investigar a percepção dos agentes comunitários de saúde sobre a violência doméstica contra a mulher em diferentes microáreas de um Município de médio porte no Sul do Brasil, em 2005.

\section{Metodologia}

Tipo do estudo: qualitativo, descritivo e exploratório. Utilizou-se o discurso do sujeito coletivo sugerido por Lefèvre e Lefèvre (2000).

Local do estudo: o Município estudado se localiza na Região Sul do Brasil. A maioria dos moradores tem descendência italiana e concentra suas atividades na agricultura e na agroindústria.

\section{População de estudo}

Foram entrevistados vinte e seis agentes comunitários de saúde (ACS), pertencentes aos vinte e cinco centros de saúde (sorteados um por centro, sendo que, num dos centros, foram entrevistados 02 ACS) da Secretaria Municipal de Saúde, que se encontravam em atividade em 2005.

Eles trabalham durante 40 horas semanais, isto é, 8 (oito) horas diárias. Suas atividades são visitas domiciliares, de acordo com a área e microárea delimitada como de sua função e abrangência. Os ACS têm a responsabilidade, com a equipe, de oferecer atenção integral às famílias, sempre com o objetivo da prevenção e da promoção da saúde da comunidade, na garantia da atenção básica do Sistema Único de Saúde (SUS).

\section{Coleta dos dados}

Utilizou-se a técnica da entrevista semiestruturada, seguindo um roteiro de perguntas pré-testadas. Iniciou-se pela gravação em fitas cassete e, em seguida, foi feita a transcrição literal dos discursos pela pesquisadora.

\section{Análise dos dados}

Trata-se de pesquisa qualitativa. Para Minayo e Sanches (1993), a importância da abordagem qualitativa acontece por uma aproximação fundamental e de intimidade entre sujeito e objeto. Nesse tipo de pesquisa, destacam-se a empatia com os motivos que levaram às ações, as intenções e os projetos dos atores a partir dos quais as ações, as estruturas e as relações entre pesquisador e pesquisados se tornam construções humanas significativas.

Lefèvre e Lefèvre (2000) sustentam que, para se trabalhar com o método qualitativo, é importante que se construa um instrumento para coleta de dados - como um roteiro - com alguns questionamentos sobre o assunto a ser pesquisado. O conjunto de respostas obtidas, a partir dessas indagações, gerará um discurso ou um pensamento encadeado discursivamente sobre o tema, e esse conjunto consistirá nas representações sociais do assunto pesquisado, 
Eu acho que é agressão. Por exemplo, quando o marido bate na mulher, envolve não só a mulher mas as crianças também; existem pais que agridem as crianças; às vezes, eu acho que quem sofre mais com isso são as crianças. Filhos batem na mãe também ou irmã, e em crianças. É violência dentro de casa! Na família. o que revela o imaginário existente sobre o mesmo.

Lefèvre e Lefèvre (2000, p.17-18) concebem as representações sociais de forma simplificada “como um conhecimento muito próximo da ação cotidiana e que tem a função de guiar, orientar, justificar essa ação”. Sendo assim, podem-se entender as representações sociais como a expressão do que pensa ou percebe determinada população ou grupo.

Foram utilizadas três figuras metodológicas para a organização dos relatos coletados (Lefèvre e Lefèvre , 2000). Inicialmente, procedeu-se à identificação da idéia central (IC), entendida como a afirmação ou afirmações que "permite $(m)$ traduzir o essencial do conteúdo discursivo explicitado pelos sujeitos em seus depoimentos" (Lefèvre e Lefèvre, 2000, p. 18). Em seguida, foram destacadas as expressõeschave (EC) que, para cada participante, constituem as transcrições literais de parte dos depoimentos, em que o pesquisador resgata o essencial do conteúdo discursivo dos segmentos que compõem o depoimento para responder às questões de pesquisa. Assim, obteve-se o produto final, o discurso do sujeito coletivo (DSC), que se propõe a "resgatar o discurso como signo de conhecimentos dos próprios discursos" (Lefèvre e Lefèvre, 2000, p.19). A partir da IC e da identificação das EC, formam-se os discursos, que retratam de modo unificado as experiências dos participantes com relação aos temas abordados.

\section{Considerações éticas}

O protocolo de pesquisa foi avaliado e aprovado por Comitê de Ética em Pesquisa.

\section{Resultados}

A entrevista semi-estruturada possibilitou a escuta dos diversos discursos dos agentes comunitários de saúde (ACS) no Programa Saúde da Família (PSF), no seu cotidiano de trabalho, relativos à Percepção dos ACS sobre a Violência Doméstica Contra a Mulher dando-lhes vez e voz no papel de protagonista na construção do Sistema Único de Saúde (SUS) no Município.
Foi portanto, possível reconstruir alguns campos de ordem subjetiva e fazer emergir questões de forma livre e espontânea a partir das vivências no trabalho de ACS, que, de outra forma, talvez não pudessem ser destacadas.

O levantamento das variáveis sociodemográficas mostrou que mais da metade dos ACS (65,4\%) residiam na zona urbana, e 34,6\% viviam em linhas e distritos na zona rural. A predominância foi de profissionais do sexo feminino, que totalizou 92\% dos entrevistados. Quanto à escolaridade, constatou-se que bem mais da metade $(65,4 \%)$ possuía o ensino médio completo. Os dados demonstraram que os ACS do Município superam a exigência do mínimo de escolaridade para o exercício da função, que é o ensino fundamental. O tempo de trabalho como ACS no PSF variou de 07 meses a 06 anos, sendo que 23,1\% estão na função desde 1999 , quando foi implantado o Programa.

a) Concepção de violência doméstica: foram observadas 06 IC, apresentadas a seguir.

IC-1: São brigas na família, dentro de casa. É agressão, quando o homem não respeita e bate na mulher, agride os filhos, os filhos agridem os pais, há abuso contra a mulher e/ou crianças tanto pelo homem quanto por parentes.

DSC: Eu acho que é agressão. Por exemplo, quando o marido bate na mulher, envolve não só a mulher mas as crianças também; existem pais que agridem as crianças; às vezes, eu acho que quem sofre mais com isso são as crianças. Filhos batem na mãe também ou irmã, e em crianças. É violência dentro de casa! Na família.

IC-2: É o homem ofender a mulher por meio da palavra, agredir verbalmente.

DSC: Para mim, violência doméstica é, para começar, agressões de palavras, às vezes alguns homens dizem assim: sua monte! Vai fazer isso, vai fazer aquilo! A partir dessas agressões de palavras, evolui para tapas.Os homens agridem verbalmente as mulheres, e elas sofrem muito com isso, às vezes elas choram, sofrem bastante!

IC-3: É o homem agredir com arma ou exigir que a mulher tenha relação sexual sem dar seu 
consentimento; é o homem levar sua mulher a “fazer ponto", quer dizer, se prostituir, o que é um desrespeito para com a mulher.

DSC: Quando ela é agredida por alguma arma ou sexualmente, porque a gente vê muitos machistas, machões, nas áreas. E também tem caso do homem que leva a mulher para fazer ponto, quer dizer, se prostitui, e ele fica em casa o dia inteiro! Sabe? E ele acha normal! E a mulher também acha normal; pra mim, isso aí é uma violência!

IC-4: É os filhos abandonarem (no afeto, na afeição, na atenção, na verdade) os pais idosos.

DSC: Tem pessoas idosas também que têm os filhos que moram junto, que são casados, vivem com a nora, e são deixados, muitas vezes, de lado, isso é um sofrimento, um abandono. As pessoas deixam os idosos meio abandonados, vivem na mesma casa, mas sentem esse abandono no afeto, na afeição, na atenção; na verdade, uma violência que eu acho assim que agride qualquer um, até as crianças que estão ao redor.

IC-5: É violência psicológica, o abuso de poder, aquela em que o marido reprime, submete, pressiona psicologicamente a mulher.

DSC: Eu acho que a violência doméstica é um abuso de poder também. Tem aquela em que ele reprime a mulher, emocionalmente, não a deixa crescer como pessoa. Alguns homens educam o filho e a mulher junto, então ela não tem liberdade para nada! Acho que isso é uma pressão psicológica em cima da mulher. Ai da mulher se o jantar não estiver pronto e tudo ajeitado quando ele chegar em casa! Eu acho que isso já é uma violência! Não precisa bater, espancar, maltratar! Isso já é um maltrato que a mulher está sofrendo.

IC-6: Violência doméstica é aquela em que a mulher ou o homem, cidadãos que são, não possuem condições mínimas de vida, pelo desemprego, falta de alimentação, de saneamento básico.
DSC: A violência gira em torno da não qualificação, talvez da mulher ou do homem, das más condições de vida em que eles vivem, das condições de alimentação, de saneamento, é uma violência que as pessoas enfrentam no seu dia a dia.

b) Sobre a violência doméstica contra a mulher. Foram identificadas 04 idéias centrais (IC) com relação aos tipos de violência percebidos:

IC-1: Violência sexual: na relação marido e esposa.

DSC: Muitas vezes, as mulheres não tão com vontade de manter relação sexual e são obrigadas pelo marido. Uma senhora relatou que ela foi violentada pelo marido dela nesse sentido, porque ela não queria, mas ele fez mesmo assim, e ela se sentiu muito mal, muito mal, e ela foi direto lá e registrou um Boletim de Ocorrência.

IC-2: Violência física: hematoma, olho roxo, soco, empurrão, marcas de faca, cortes, puxão de cabelo, ferro quente no corpo, dormir ao relento e espancamento, acompanhados do alcoolismo.

DSC: Eu já observei mulher com olho roxo, hematoma no corpo, por ter levado soco do marido, até marcas de faca. Presenciei as crianças sofrendo, gritando, pedindo ajuda, pois o pai iria acabar matando a mãe! Já vi mulher que foi espancada pelo marido, marido que bebe demais $e$ às vezes espanca a mulher. Até de encostarem ferro quente na mulher! Esquentam um ferro e colocam na mulher quando estão bêbados. Já cansei de ver homem puxar a mulher pelos cabelos, deixá-la dormir ao relento! Espancamento também! Socando, empurrando. [Elas] vêm pra unidade [de saúde] cortadas, às vezes elas mentem. É, isso eu já vi, como aquela propaganda na televisão, dizem que caiu a lata na cabeça...mas na verdade não caiu, na verdade foi o marido que bateu! Apareceu com olho roxo, coisa e tal.

IC-3: Econômica ou financeira: fome, falta de alimentação, desemprego, abandono, negligência do homem com relação aos filhos e esposa ao deixá-los passar fome, necessidades.
Eu acho que a violência doméstica é um abuso de poder também. Tem aquela em que ele reprime a mulher, emocionalmente, não a deixa crescer como pessoa. Alguns homens educam o filho e a mulher junto, então ela não tem liberdade para nada! Acho que isso é uma pressão psicológica em cima da mulher. A da mulher se o jantar não estiver pronto e tudo ajeitado quando ele chegar em casa! Eu acho que isso já é uma violência! Não precisa bater, espancar, maltratar! Isso já é um maltrato que a mulher está sofrendo. 
DSC: Eu tenho na minha área paciente que relata que o marido bebe muito e deixa as crianças passarem fome, e que brigam bastante. As queixas são mesmo de fome. O marido está desempregado, mas agressão física, não.

IC-4: Violência psicológica, moral. O marido e até os filhos violentam psicologicamente, diminuem a auto-estima da mulher; machismo: o marido não respeita a vontade da mulher/ esposa; tem ciúme; não deixa a mulher estudar, trabalhar fora, cortar, pintar os cabelos; desrespeito com a esposa.

DSC: Dá para perceber que os esposos são ruins, eles não precisariam agredir, bater, machucar. Mesmo com palavras, eles agridem. Agride verbalmente a mulher, chama de tudo quanto é nome, ele chama! Chama de porca, de tudo! É vadia, burra, tonga, xingão, é porque você não faz nada, você não vale nada, vagabunda, idiota que não sabe nada, porque sou só eu quem faz as coisas aqui, só eu que ponho dinheiro dentro de casa; eles acham que, porque trabalham fora e a mulher fica em casa, ela não faz nada. É mais moral, mesmo. Há mulheres que ficam trancadas em casa porque o marido não deixa sair, tem ciúmes, não deixa trabalhar fora, não deixa estudar, esse tipo de coisa. Houve marido que trouxe a outra para dormir dentro da casa! O que aconteceu: a mulher tentou até o suicídio! Algumas me disseram que gostariam muito de cortar e pintar o cabelo, mas o marido não deixa. Eu acho que prevalece bastante, aqui no interior, o machismo. É uma violência!

c) Sobre a concepção de saúde: 05 ICs foram observadas.

IC-1: Saúde é um direito (a um bom e rápido atendimento) de todos e dever do Estado sem discriminações, com eqüidade.

DSC: É o bem-estar físico mental e social, e a saúde é um direito de todos e dever do Estado. Mas é um direito de todos e tem que saber aproveitar, usufruir isso! Saúde é um direito de todo e qualquer cidadão.

IC-2: Saúde é um direito, mas também é um dever do cidadão cuidar de sua saúde e prevenirse de doenças, utilizando os serviços oferecidos gratuitamente pelo SUS.

DSC: Saúde, ao meu ver, é um direito de todos. Um direito e um dever do cidadão também porque, já que tem tantas portas abertas para tantos exames, para tantas coisas, o paciente pode chegar e ser atendido, receber atendimento gratuito e tal; eu acho que, muitas vezes, o paciente não enxerga como portas abertas, preventivo, mas a saúde é um direito de todos e tem que saber aproveitar, usufruir.

IC-3: Saúde é um conjunto, o todo: bem-estar físico, mental, psicológico e social; condição de vida saudável, boa alimentação, ter onde morar, estudar, trabalhar, relacionar-se bem com as pessoas da família, amigos e vizinhos. Estar feliz. Estar doente é apenas um detalhe na vida da pessoa se ela estiver bem em todas as áreas e no contexto familiar.

DSC: Saúde é estar bem... Saúde pra mim envolve vários fatores; a pessoa tem que estar bem em todas as áreas para tu ter saúde, ter uma boa saúde física, mental, psicológica também, principalmente; ter uma casa, moradia, água, luz, que geralmente algumas pessoas que não possuem, isso pode prejudicar a saúde. Não pense que, se os pais brigam dia e noite dentro de casa, os filhos terão uma saúde boa ou a mãe, e mesmo o pai também.

IC-4: Saúde não é só deixar de sentir dor. As pessoas confundem doença, algo físico, com a “dor” emocional, que pode surgir de outras coisas/ situações. Só o remédio não resolve a falta de condições mínimas de vida saudável, como ter onde morar, trabalho, alimentação.

DSC: A saúde é tudo, não adianta a pessoa vim aqui [ao posto de saúde] para se consultar porque está com uma dor; às vezes essa dor vem de outras causas. Então para mim, saúde já começa ali: ter onde morar, ter pelo menos as condições mínimas para viver. Eu acho que saúde não é só a saúde física, não ter dor! Existe a saúde emocional. Se a pessoa não vive bem 
emocionalmente, ela com certeza não vai estar bem.

IC-5: Saúde começa com a higiene. É ter um ambiente bom, limpo, carinho, comportamento carinhoso dos pais com os filhos, condição de vida boa.

DSC: Saúde é a higiene, a higiene em primeiro lugar para ter saúde; eu acho que o que vale para tua saúde é tudo. Higiene, carinho, comportamento dos pais! Saúde é a pessoa ter um ambiente bom, limpo, e ele assim, vamos dizer, tem tudo. Não é ter dinheiro, mas ter uma vida boa. Não havendo higiene, não existe saúde.

d) Sobre associação entre violência doméstica e condições socioeconômicas das pessoas: 02 ICs.

IC-1: Sim, existe associação, pelas condições de carência econômica em que as pessoas vivem, a pobreza, a situação financeira, o desemprego, a falta de cultura, de educação e informação; os meios de comunicação imbutem necessidades na cabeça das crianças, e tudo isso acaba gerando desentendimentos, frustrações e impotência, até violência entre os casais/família.

DSC: Eu acho que existe, porque, quando está faltando alguma coisa na casa, quando a mulher não tem emprego, e, muitas vezes, o homem está desempregado, eu acho que tudo, tudo vem gerar uma coisa da outra: a pobreza com a agressão.

IC-2: Não há associação entre as condições socioeconômicas e a violência doméstica. Tanto em classe social alta, média ou baixa, tanto pobre quanto rico, religiões diferentes, pode ser observada violência contra a mulher e/ou na família. O que diferencia, o que muda entre as classes é o tipo de agressão/violência cometida.

DSC: Eu acredito que não! O dinheiro não faz diferença se a pessoa quer agredir ou não! Se quer sair com uma outra mulher ou não, se quer bater na mulher ou não, se ele acha que pode beber, isso acontece tanto com o pobre quanto com o rico; o pobre, se não tem dinheiro, dá um jeito para beber! E o rico também! Eu penso que isso não interfere tanto no financeiro. Portanto, eu não sei se existe [essa associação], porque a gente não vê só na favela ou só em classe baixa, a gente vê muito disso também em classe média ealta.

e) Sobre associação entre violência doméstica e uso de álcool e/ou drogas pelas mulheres e/ou seus companheiros: 1 IC.

IC-1 Há associação.

DSC: Sim, tem. Do marido que bebe demais e às vezes espanca a mulher. Quase sempre consomem álcool, droga não é muito [freqüente], mas tem homens e mulheres que usam. Uso de droga e álcool. Muitos homens usam álcool. Elas bebem, mas não querem ser alcoólatras, mas a gente vê que elas já estão dominadas pelo vício, e os homens, quase todos! Geralmente acontece mais [a violência] nos finais de semana, as pessoas abusam um pouco e vão além, aí acontecem as brigas.

f) Quem é o agressor: 3 ICs.

IC-1: É o homem: marido, companheiro.

DSC: Agressor? Sempre o homem, e a vítima é a mulher; geralmente, 99\% é o homem quem agride a mulher. Companheiro, marido, namorado, parceiro.

IC-2: É o homem: pai, e filhos.

DSC: O pai que agride a filha. O que mais aparece é isso! Tem alguns casos que os filhos também; por motivo de droga, eles se tornam violentos, $e$ sempre a mãe é que vai estar ali, para dar a cara a tapa.

IC-3: O homem e a mulher.

DSC: Às vezes algumas mulheres começam [a briga] também! Não é só o homem, não, colocar a culpa só no homem, porque mulheres também brigam e discutem.

g) A reação das mulheres face à violência: 5 ICs. 
IC-1: As mulheres comentam com os ACS.

DSC: A maioria fica quieta! Elas até desabafam com a gente, mas elas não têm coragem de ir a uma delegacia denunciar esse tipo de coisa.

IC-2: Há mulheres que denunciam na delegacia, e outras sofrem, mas ficam agüentando; poucas reagem denunciando, ficam caladas, intimidadas pelo medo de serem abandonadas, de apanhar novamente ou pela ameaça de morte.

A maioria fica quieta! Elas até desabafam com a gente, mas elas não têm coragem de ir a uma delegacia denunciar esse tipo de coisa.
DSC: Algumas se queixam na delegacia. E daí prendem o marido, quando elas se queixam. Tem umas que permanecem caladas! Tem aquelas que apanham e pensam assim: se eu for lá e der queixa, meu marido vai me deixar! E tem aquele marido que agride e diz assim: se tu for lá fazer queixa, eu te mato! Então, a maioria sofre, mas fica calada.

IC-3: Ficam tristes, caem em depressão, choram envergonhadas, calam-se e escondem o fato, pois talvez se sintam inferiores.

DSC: Para começar, elas ficam muito tristes, têm vergonha de contar! Elas têm vergonha! Eu sei, a mulher ainda reage muito mal! Porque ela esconde! Ela não costuma mostrar, não costuma se defender, não costuma procurar ajuda, procurar uma defesa, uma delegacia de defesa da mulher.

IC-4: As mulheres se revoltam e agridem também.

DSC: Ah, algumas se revoltam e partem pra agressão também, outras caem numa depressão muito profunda, se fecham!

IC-5: As mulheres sofrem violência, às vezes pedem ajuda para o ACS e querem que ele resolva o problema.

DSC: Olha, algumas tentam te colocar [a par da situação] e explicar, querendo que a gente resolva o problema delas.

\section{Discussão}

A análise dos dados, através dos discursos e da observação cotidiana no trabalho dos ACS, mostrou que existe violência doméstica contra a mulher perpetrada pelo marido/companheiro dentro dos lares. Deslandes et al. (2000) desenvolveram estudo em dois hospitais públicos, no Município do Rio de Janeiro, e encontraram como resultado que a maioria das agressões foram praticadas no interior da residência (83,3\% dos casos). Essa prática foi recorrente, o que, segundo os autores, legitima a agressão pela facilidade encontrada no interior do lar. Além disso, o agressor costuma ser o marido, na maioria dos casos (56,9\%). Nossa pesquisa também registrou essa realidade.

O estudo encontrou violência física, sexual, psicológica e econômica. Um único episódio de violência física pode intensificar enormemente o significado e o impacto do maltrato emocional (OMS/OPS, 1998), pois a mulher tem relatado que o pior aspecto dos maus tratos não é a violência em si mesma, mas a "tortura mental" e "viver com medo e aterrorizada" (OMS/OPS, 1998). A mulher ainda reage pouco, conforme o DSC, pelo menos em relação à denúncia do fato, seja por medo de ameaças do companheiro seja por vergonha em realizar a denúncia.

Em muitas sociedades, a mulher não entende o sexo forçado como violência, caso ela esteja casada ou vivendo com o agressor. Alguns países, porém, já reconhecem o estupro, no matrimônio, como crime; outros continuam dizendo que o esposo tem o direito legal de acesso sexual ilimitado à esposa. As pesquisas de vários países indicam que 10 a $15 \%$ das mulheres revelam que os maridos as obrigam a ter relações sexuais (OMS/OPS, 1998). O medo de ser abandonada pelo companheiro, a responsabilidade com os filhos e as dificuldades financeiras também constituem fatores que contribuem para seu silêncio. Blay (2003) explica que, para o enfrentamento de uma cultura machista (de gênero), fazem-se necessárias políticas públicas transversais que, em suas intervenções, vão modificando a discriminação e a incompreensão sobre os direitos das mulheres e passando a assimilar o fato de que os direitos das mulheres fazem parte dos direitos humanos. A tristeza, o choro, o desespero e o silêncio são consideradas reações próprias das mulheres, e 
ficar calada ou reagir brigando ainda são alternativas encontradas pelas vítimas para sufocarem seus sentimentos e irem vivendo. Adeodato et al (2005) mostram que, em 64\% dos casos levantados em Delegacia da Mulher, no Ceará, as mulheres reagiram verbalmente ou fisicamente às agressões.

A violência acontece não só contra a mulher, mas entre e com outros membros da família, concebida pelos agentes como aquela que acontece dentro de casa, no âmbito da família, muitas vezes associada ao uso de álcool e/ou drogas. Azevedo (1986) comenta que o uso de álcool nas situações de agressão tem estado associado e tem potencializado a violência, já que, em mais da metade dos registros pesquisados no Município de São Paulo, o papel do álcool como catalisador e potencializador de violência esteve presente nas queixas de vítimas.

A condição socioeconômica pode estar associada à violência, porém um grupo de ACS considerou que pode haver violência tanto em lares de pessoas ricas quanto pobres, tanto na classe alta quanto na média, podendo variar apenas o tipo da violência.

Ao discutir a concepção do ACS sobre saúde, percebeu-se que esta não esteve associada à utilização de serviços médicos e de fármacos. A concepção de saúde do ACS esteve associada a um bem-estar completo, a condições de vida saudáveis e sem violência. Apresenta-se não só como dever do Estado, mas também como dever do cidadão de cuidar de sua saúde, a partir do direito já preconizado e garantido constitucionalmente. Pessini e Barchifontaine (2000) afirmam que a sociedade precisa compreender que ter saúde é muito mais do que não estar doente: é poder viver em condições de dignidade. Lutar pela saúde é mais do que lutar por mais postos e centros de saúde, hospitais, profissionais de saúde, medicamentos e outros; é lutar pela própria vida, e vida em plenitude e abundância. Nas atribuições do ACS, o atendimento aos casos de violência na família determina, em primeiro lugar, que o agente precisa ter conhecimento das leis e instituições e que possam encaminhar para o apoio as pessoas vítimas de violência (MINISTÉRIO DA SAÚDE, 2002). O documento aborda a importância de o agente lidar com a violência na família, na ajuda às pessoas envolvidas, sem discriminá-las, entendendo que as vítimas e os agressores são seres humanos e cidadãos com iguais direitos de receberem ajuda e orientação. Os ACS devem registrar suas impressões e levar o problema para, com o instrutor-supervisor, buscarem soluções para a ação. No entanto, os ACS, no Município estudado, até o presente momento, não haviam recebido capacitação específica para a abordagem sobre violência nas famílias.

\section{Conclusões}

O estudo pretendeu, a partir de algumas questões de pesquisa, aprofundar o conhecimento sobre o fenômeno violência doméstica no Sul do Brasil, retirando da clandestinidade um problema grave que, há tempo, vem sendo tratado como de foro íntimo das pessoas nele envolvidas.

Os discursos demonstram que as mulheres têm um papel social inferiorizado diante de seus companheiros, e, no cotidiano, possuem tarefas domésticas ditas como essencialmente pertencentes às mulheres. $\mathrm{O}$ ritmo de trabalho intenso fora do lar não exclui suas obrigações em realizar tarefas dentro do lar. A obediência aos maridos/companheiros vai desde o cuidado pessoal até o desempenho sexual.

A vergonha pela violência sofrida é infinitamente maior do que a coragem da mulher para denunciar. Há uma grande contradição nos sentimentos das mulheres: o medo de que a violência possa ser recorrente e, ao mesmo tempo, a crença de que não mais irá acontecer também desestimulam a mulher. O limite para o enfrentamento da vergonha pode ser o do insuportável, respeitada toda e qualquer diferença individual de cada ser humano.

Podemos constatar que o ACS pode ser o elo entre a vergonha e a coragem para a mulher denunciar o problema da violência, o que significa 
que ele parece ser de fundamental importância no acolhimento das angústias dessas mulheres: no encorajamento para o relato de sofrimento, na detecção da questão da violência, que pode estar acompanhada pela depressão, ansiedade ou até mascarada por algum tipo de queixa vaga, e, em conseqüência, fazer o encaminhamento de referência correto e eficiente na denúncia.

Os ACS apontam uma responsabilização da mídia em relação à violência que acontece nas famílias, pois ela cria necessidades para as pessoas, crianças e adultos. Os meios de comunicação incutem necessidades na cabeça das crianças, o que leva ao consumismo; no entanto, a falta de condições financeiras, de poder de compra e o próprio desemprego acabam gerando desentendimentos, frustrações e impotência, até violência entre os casais/ família.

O ACS, em certo momento, parece responsabilizar os usuários pela sua própria saúde, numa lógica simplista: os serviços de saúde existem, é um direito do cidadão o serviço, portanto, ele também é responsável, deve procurar a unidade de saúde e prevenir-se de doenças! De que forma a informação chega até as pessoas, o processamento das mesmas, enfim, o jeito de viver em sociedade não é considerado pelos ACS.

Sabendo da provisoriedade do conhecimento, sugere-se que levantamentos quantitativos e qualitativos ainda sejam foco de pesquisas em relação ao fenômeno violência doméstica, pois, até o presente momento, não foram encontradas informações, dados que tenham a possibilidade de abranger a amplitude das suas conseqüências sociais. A violência contra a mulher está presente nos lares e precisa ser denunciada e tratada como crime no âmbito jurídico, fazendo-se respeitar e valer os direitos da mulher, e, como questão de saúde pública, deve ser foco de atenção na promoção e prevenção da violência contra a mulher, entendendo-se saúde como um processo de construção da autonomia dos seres humanos. Para tanto, mecanismos de proteção à mulher vítima de violência também precisam ser criados.

Em seu sentido mais amplo de saúde, devem ser construídas melhores condições de vida através de ações coletivas e individuais, o que diminuiria as desigualdades entre os que vivem em sociedade e, mais especificamente, as desigualdades de saúde. Sabe-se que existem leis específicas no País, no entanto, é preciso que as mesmas sejam incorporadas pela sociedade como cultura política, para que nas ações, no âmbito das políticas públicas, haja a participação ampla da sociedade no atendimento das necessidades da população. Por vezes, as leis são desconsideradas pelas práticas governamentais e sociais, como é o caso da inexistência do serviço de notificação compulsória da violência doméstica contra a mulher no Município estudado até o presente momento.

Consideramos necessário, a partir do pedido dos próprios ACS, que, durante as entrevistas, sejam oferecidos subsídios teórico-práticos aos mesmos para que, em seu trabalho cotidiano, possam detectar situações de violência, saber a forma de abordar as famílias e dar encaminhamentos de referência tanto para os casos de violência quanto para os de uso de álcool/drogas.

Espera-se, com esta pesquisa, contribuir para a produção do conhecimento, para a criação de novos espaços de discussão, de dispositivos de intervenção em relação ao fenômeno violência doméstica, corroborando a contribuição que o campo da saúde coletiva pode dar tanto para a Psicologia quanto para a sociedade. 


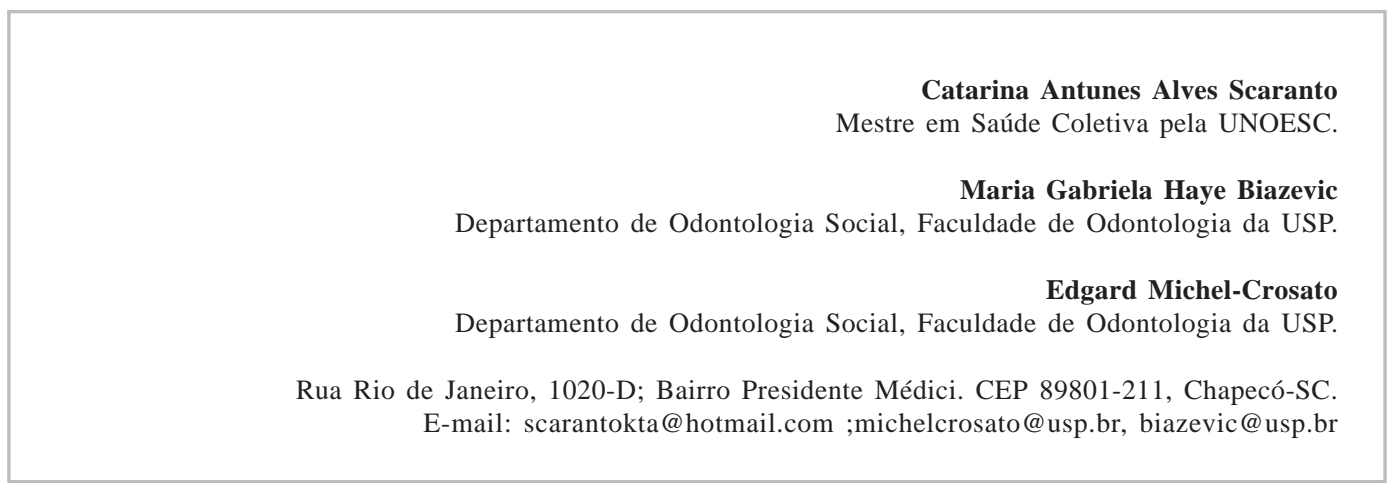

Recebido 12/07/06 Reformulado 23/03/07 Aprovado 02/04/07

ADEODATO, V.G; CARVALHO, R.R.; SIQUEIRA, V.R.; SOUZA, F.GM. Qualidade de vida e depressão em mulheres vítimas de seus parceiros. São Paulo: Rev. Saúde Pública, 39(1), p.108-13,2005.

ALVES, A.M.; COURA-FILHO, P. Avaliação das ações de atenção às mulheres sob violência no espaço familiar, atendidas no Centro de Apoio à Mulher (Belo Horizonte) entre 1996 e 1998. Rio de Janeiro: Ciência \& Saúde Coletiva, 6 (1), p.243-257, 2001.

AZEVEDO, M.A. Mulheres espancadas/violência denunciada: repensando a problemática. Temas IMESC,1986. Soc. Dir. Saúde, São Paulo, 3 (2), p.129-149, 1986.

BLAY, E.A. Violência contra a mulher e políticas públicas. São Paulo: Estudos Avançados, 17(49), p.87-93, 2003.

BRASIL. Constituição da República Federativa do Brasil. Texto constitucional de 5 de outubro de 1988, contendo as alterações adotadas pelas Emendas Constitucionais $n^{\circ} 1 / 92$ a 15/96 e pelas Emendas Constitucionais de Revisão $\mathrm{n}^{\circ} 1$ a 6/94. 2ª̀. Brasília: Imprensa Nacional, Divisão de Editoração, 1997.

CÓDIGO PENAL. Legislação brasileira. Decreto-lei n ${ }^{2}$ 2.848, de 7 12-1940, atualizado. 43a ed. São Paulo: Saraiva, 2005.

DESLANDES, S.F.; GOMES, R.; SILVA, C.M.F.P. Caracterização dos casos de violência doméstica em dois hospitais públicos do Rio de Janeiro. Cad. Saúde Pública, Rio de Janeiro, 16(1), p.129-137, 2000.

IBGE. Instituto Brasileiro de Geografia e Estatística; Ministério do Planejamento, Orçamento e Gestão. População residente-Censo 2000: Brasil, unidades da Federação e Municípios, 2000 [base de dados na internet]. Rio de Janeiro:IBGE, 2000. Disponível em: http:/ /www.ibge.gov.br

LEFÈVRE, F.; LEFÈVRE, A.M.C. Os novos instrumentos no contexto da pesquisa qualitativa. In:LEFÈVRE, F;; LEFÈVRE,A.M.C.; TEIXEIRA, J.J.V.
(Orgs). O discurso do sujeito coletivo. Uma nova abordagem metodológica em pesquisa qualitativa. Caxias do Sul-RS: Educs, 2000. p.11-35.

MINAYO, M.C.S; SANCHES, O. Quantitativo-qualitativo:oposição ou complementaridade? Cad. Saúde Pública. Rio de Janeiro, 9(3), p. 239-262, 1993.

MINISTÉRIO da Saúde. Secretaria de Políticas de Saúde. Violência intrafamiliar: orientações para a prática em serviço.Cadernos de Atenção Básica,n ${ }^{\circ}$, série A-Normas e Manuais Técnicos nº131, Brasília-DF, 2002.

MINISTÉRIO da Saúde. Portal da Saúde. Violência contra a mulher: notificação compulsória. Acesso em 24/11/2005. Disponível em www.saude.gov.br,<http://portalweb05.saude.gov.br/portal/ aplicacoes/noticias/noticias_detalhe.cfm?co_seq_noticia=12088 >.

ORGANIZACIÓN PANAMERICANA DE LA SALUD-OMS/ OPS.Violencia contra la mujer, un tema de salud prioritario. Washington (DC): División de Salud Familiar y Reproductiva; División de Salud y Desarrollo Humano. Junio, 1998.

PESSINI, L.; BARCHIFONTAINE, C.P. Problemas atuais de bioética. São Paulo: Edições Loyola, 2000.

SAFFIOTI, H.I.B. Violência de gênero no Brasil atual. In: Estudos Feministas, número especial, Rio de Janeiro,CIEC, p.443-461, 1994.

SCHRAIBER, L.B.; d'OLIVEIRA,A.F.PL.; FRANÇA-JÚNIOR, I.; PINHO, A.A. Violência contra a mulher: estudo em uma unidade de atenção primária à saúde. São Paulo: Rev. Saúde Pública, 36(4),p. 470-7, 2002.

SOARES, B.M. Mulheres invisíveis: violência conjugal e as novas políticas de segurança. Rio de Janeiro: Civilização Brasileira, 1999.

\section{Referências}

